\title{
Determination of fenhexamid residues in grape must, kiwifruit, and strawberry samples by enzyme-linked immunosorbent assay
}

\author{
Francesc A. Esteve-Turrillas, Antonio Abad-Fuentes, and Josep V. Mercader*
}

5

Institute of Agrochemistry and Food Technology, Spanish National Research Council, P.O. Box 73, 46100 Burjassot, València, Spain.

* Corresponding author. Tel. +34-963900022 ext. 2316, Fax. +34-963636301, e-mail: jvmercader@iata.csic.es

10

Running title: Determination of fenhexamid residues in fruit samples by ELISA

\begin{abstract}
Fenhexamid is a last-generation agrochemical extensively used nowadays to protect high

15 valuable crops and fruits from fungus attacks. In this paper, the development of an indirect competitive immunoassay for the determination of fenhexamid residues in fruit samples is described. After optimization of immunoreagent concentrations, the assay, based on monoclonal antibody FHo4\#27, showed high sensitivity and selectivity, with a limit of detection for fenhexamid standards in buffer of $0.04 \mu \mathrm{g} / \mathrm{L}$. The influence on the analytical parameters of the standard curve of several physico-chemical factors, including $\mathrm{pH}$, ionic strength, presence of solvents, and matrix interferences was studied. For spiked liquid food samples like grape must, just a direct 1:50 dilution in water was sufficient to attain recoveries between 100 and $110 \%$. For kiwifruit and strawberry samples, a double extraction procedure with methanol is proposed in this study, which afforded recovery values that ranged between 103 and $116 \%$. The limit of quantification of the developed assay was $5 \mu \mathrm{g} / \mathrm{kg}$ for grape must, $10 \mu \mathrm{g} / \mathrm{kg}$ for kiwifruits, and $25 \mu \mathrm{g} / \mathrm{kg}$ for strawberries. The
\end{abstract}


optimized assay was compared with a reference procedure based on liquid chromatography using incurred samples from the market, and an excellent correlation between both methods was found.

Keywords: fenhexamid, fungicide, pesticide residues, monoclonal antibody, immunoassay, ELISA, 30 hapten, validation, rapid methods, food safety.

\section{Introduction}

Fenhexamid (FH) was introduced in 1999 as a fungicide to control Botrytis cinerea and related pathogens in fruit, vegetables, and ornamental plants. This disease, so-called grey mould, considerably affects crops in the field and during fruit storage, even at refrigeration temperatures. FH formulations, containing $50 \%(\mathrm{w} / \mathrm{w})$ active ingredient, are commercialized by Bayer CropScience AG (Manheim am Rhein, Germany) under different trade names such as Teldor ${ }^{\circledR}$ and Password ${ }^{\circledR}$, and also by Arysta LifeScience (Cary, NC, USA) as Elevate ${ }^{\circledR}$ and Decree ${ }^{\circledR}$. This ultimate generation pesticide inhibits the biosynthesis of ergosterol by a particular and new mode of action, which makes it particularly valuable for combined programs aimed to avoid the sprout of resistance (Suty, Pontzen \& Stenzel, 1999; Roßlenbroich, 1999). According to the last EU Annual Report on Pesticide Residues (EFSA, 2009) published by the European Food Safety Authority (EFSA) for the year 2007, FH was the $11^{\text {th }}$ most frequently found pesticide in fruits and vegetables,

45 whereas it ranked $6^{\text {th }}$ in 2006. Čuš and coworkers (Čuš, Česnik, Bolta \& Gergorčič, 2010) have recently found that $44 \%$ of the analyzed wine samples contained FH. Residues of this fungicide are considered as very persistent due to their stability and resistance to hydrolysis. However, its toxicity to mammals is low, with oral and dermal $\mathrm{LD}_{50}$ in rats of $5000 \mathrm{mg} / \mathrm{kg}$, so it does not represent acute hazard under normal uses (FAO/WHO, 2005). The EU maximum residue limits (MRLs) for FH in

50 fruits are for example: $10 \mathrm{mg} / \mathrm{kg}$ for kiwifruits and canefruits, and $5 \mathrm{mg} / \mathrm{kg}$ for grapes, strawberries, apricots, cherries, and peaches (EC Regulation, 2008). 
During the present decade, some papers have been published describing different analytical methodologies for the analysis of FH residues in fruits and vegetables (Table 1). Most of these studies used either gas chromatography (GC) or high performance liquid chromatography (HPLC). In those studies, samples were usually extracted by means of organic solvents, mostly with the aid of a homogenizer, although ultrasonic extraction with methanol has also been employed for FH recovery from strawberry samples (see Table 1 for references). More recent studies used QuEChERS (Quick, Easy, Cheap, Effective, Rugged and Safe) methodology (Anastassiades, Lehotay, Štajnbaher \& Schenck, 2003) for the multiresidue analysis of FH and other pesticides in grapes, lemons, onions, tomatoes, pears, and oranges (Lesueur, Knittl, Gartner, Mentler \& Fuerhacker, 2008; Kmellár et al., 2008). However, the aforementioned methodologies have a low sample throughput, require expensive equipment, and high amounts of used solvents ought to be processed, which considerably increase the cost of assays in routine analysis.

Recently, a FH derivative was synthesized and high-affinity and selective monoclonal antibodies (mAbs) against FH were produced in our lab (Mercader \& Abad-Fuentes, 2009) and they were characterized by enzyme-linked immunosorbent assay (ELISA). Now, in this study, we describe the development of an immunoassay using the conjugate-coated indirect competitive ELISA format for the easy determination of FH residues in liquid foodstuffs and fruits. Because solid food samples require a previous extraction step, different alternatives were evaluated for the quantitative recovery of fungicide residues from kiwifruits and strawberries. Finally, the proposed methodology was validated in terms of sensitivity, selectivity, and accuracy, and it was compared with a reference procedure based on HPLC measurements using incurred fruit samples from local markets.

\section{2. Experimental}

\subsection{Reagents and instruments}


Sephadex G-25 HiTrap desalting columns from General Electric Healthcare (Uppsala, Sweden) were used to purify protein conjugates. Ultraviolet-visible spectra and ELISA 80 absorbances were read with a PowerWave HT microplate reader from BioTek Instruments (Winooski, VT, USA). ELISA plates were washed with an ELx405 microplate washer also from BioTek Instruments. A Hitachi (Tokyo, Japan) L-2130 high performance liquid chromatography system, equipped with a Hitachi L-4500 diode array detector and a Merck KGaA (Darmstadt, Germany) LiChroCART RP-18 column $(250 \mathrm{~mm} \times 4 \mathrm{~mm}, 5 \mu \mathrm{m})$ was employed for

85 chromatographic separations. Costar flat-bottom high-binding polystyrene ELISA plates were from Corning (Corning, NY, USA). An Eppendorf 5804 centrifuge (Hamburg, Germany) was used for solid-particle separation from samples. Polyclonal rabbit antimouse-immunoglobulin peroxidase conjugate (RAM-HRP) was from Dako (Glostrup, Denmark), and ovalbumin (OVA), 1-(4pyridyl)-3-phenylurea (PPU), and o-phenylenediamine (OPD) were from Sigma-Aldrich (Madrid,

90 Spain). Methanol, ethanol, acetonitrile, dimethylformamide (DMF), and anhydrous magnesium sulphate were obtained from Scharlau (Barcelona, Spain). Hydrogen peroxide (30\%), sulfuric acid (95\%), hydrochloric acid (37\%), and sodium chloride were purchased from Prolabo-VWR International Eurolab S.L (Barcelona, Spain). Analytical grade FH (2',3'-dichloro-4'-hydroxy-1methylcyclohexanecarboxanilide) and other pesticide standards were acquired from Fluka/Riedel-

95 de-Haën (Seelze, Germany). Concentrated working solutions were prepared in DMF and methanol for ELISA and HPLC analysis, respectively, and kept at $-20{ }^{\circ} \mathrm{C}$ in amber glass vials. Fruit and must samples were directly purchased from local markets and stored at $4{ }^{\circ} \mathrm{C}$. Solid samples were chopped and homogenized using a T-25 ultra-turrax blender from IKA (Staufen, Germany).

\subsection{Preparation of protein-hapten conjugates}

In this study, a synthetic FH derivative [4-(2',3'-dichloro-4'-(1methylcyclohexanecarboxamido)phenoxy)butanoic acid] (FHo4, see Fig. 1) was used, which had been obtained by reaction of FH with ethyl 4-bromobutyrate and subsequent hydrolysis of the ester, 
as described in a previous article (Mercader et al., 2009). Using this hapten, protein conjugates were prepared by activation of the free carboxylic group of FHo4 and subsequent reaction with the free amine groups of the OVA protein. Two conjugates with different hapten-to-protein molar ratios (MR) were prepared. Briefly, $18 \mu \mathrm{mol}$ of hapten was dissolved in $180 \mu \mathrm{L}$ of DMF and mixed with $18 \mu \mathrm{mol}$ of tributylamine and $18 \mu \mathrm{mol}$ of isobutyl chloroformate also in DMF. The concentration of all reagents in the mixture was brought to $90 \mathrm{mM}$ with additional DMF and the activation reaction was let to proceed during $1 \mathrm{~h}$ at room temperature. Next, 10 or $50 \mu \mathrm{L}$ of activated hapten solution was added drop wise to two vials, each one containing $1 \mathrm{~mL}$ of a $15 \mathrm{~g} / \mathrm{L} \mathrm{OVA}$ solution in $50 \mathrm{mM}$ carbonate-bicarbonate buffer, $\mathrm{pH}$ 9.6. Therefore, the initial hapten-to-protein ratios in the reaction mixture were $2.5: 1$ and 12.5:1. The coupling reaction was allowed during $2.5 \mathrm{~h}$ at room temperature with moderate stirring. Finally, the conjugate was separated from uncoupled hapten by gel filtration

115 on Sephadex G-25, using $100 \mathrm{mM}$ sodium phosphate buffer, $\mathrm{pH} 7.4$ as eluent. The degree of hapten-to-protein conjugation was measured spectrophotometrically from the absorbance value at $280 \mathrm{~nm}$ by assuming that the molar absorption coefficients of the hapten and the protein were the same for the free and the conjugated forms. Spectroscopic characterization indicated that the achieved MRs of the two available conjugates were around 5 and 1 . The purified conjugate was 120 diluted to $1 \mu \mathrm{g} / \mathrm{L}$ with $100 \mathrm{mM}$ sodium phosphate buffer, $\mathrm{pH} 7.4$ and stored at $-20{ }^{\circ} \mathrm{C}$ in amber vials.

\subsection{ELISA procedure}

Immunoassays were performed in the conjugate-coated indirect competitive ELISA format

125 (ic-ELISA). Usually, ninety-six-well polystyrene ELISA plates were coated with $100 \mu \mathrm{L}$ per well of OVA-conjugate solution in $50 \mathrm{mM}$ carbonate-bicarbonate buffer, $\mathrm{pH} 9.6$ by overnight incubation at room temperature. Coated plates were washed four times with washing solution $(0.15 \mathrm{M} \mathrm{NaCl}$ containing $0.05 \%$ Tween 20 ) and then they received $50 \mu \mathrm{L}$ per well of analyte solution plus $50 \mu \mathrm{L}$ per well of mAb solution. From a $30 \mathrm{mg} / \mathrm{L} \mathrm{FH} \mathrm{stock} \mathrm{solution} \mathrm{in} \mathrm{DMF,} \mathrm{calibration} \mathrm{curves} \mathrm{in} \mathrm{the} 60$ 
130 to $0.004 \mu \mathrm{g} / \mathrm{L}$ range were prepared by 5 -fold serial dilution in water or PBS (10 $\mathrm{mM}$ sodium phosphate buffer with $137 \mathrm{mM} \mathrm{NaCl}, 2.7 \mathrm{mM} \mathrm{KCl}, \mathrm{pH}$ 7.4). A blank was included in each curve. The immunological reaction took place for $1 \mathrm{~h}$ at room temperature, and plates were washed again as described. Next, $100 \mu \mathrm{L}$ per well of a 1:2000 dilution of RAM-HRP conjugate in PBS containing $0.05 \%$ Tween 20 (PBST) was added, and plates were incubated $1 \mathrm{~h}$ at room temperature.

135 After the plates had been washed as described, the retained peroxidase activity was determined by addition of $100 \mu \mathrm{L}$ per well of freshly prepared developing solution containing $2 \mathrm{~g} / \mathrm{L}$ OPD and $0.012 \%(\mathrm{v} / \mathrm{v}) \mathrm{H}_{2} \mathrm{O}_{2}$ in $25 \mathrm{mM}$ citrate and $62 \mathrm{mM}$ phosphate buffer, $\mathrm{pH}$ 5.4. The enzymatic reaction was stopped after $10 \mathrm{~min}$ at room temperature by addition of $100 \mu \mathrm{L}$ per well of $2.5 \mathrm{M}$ sulfuric acid. The absorbance was immediately read at $492 \mathrm{~nm}$ using $650 \mathrm{~nm}$ as reference wavelength. The 140 resulting sigmoidal curves were mathematically fitted to a four-parameter logistic equation using the SigmaPlot software package from SPSS Inc. (Chicago, IL, USA), and from these curves, assay sensitivity was estimated as the concentration of analyte that reduced $50 \%\left(\mathrm{IC}_{50}\right)$ the maximum absorbance signal $\left(\mathrm{A}_{\max }\right)$ reached at the zero dose of analyte. For immunoreagent evaluation, competitive assays were performed in a bidimensional mode, as previously described (Mercader, 145 Suárez-Pantaleón, Agulló, Abad-Somovilla \& Abad-Fuentes, 2008). Briefly, in ELISA plates coated with two concentrations of the OVA-FHo4 conjugate, competitive assays were carried out with FH standard curves in PBS and several mAb concentrations in PBST.

For kiwifruit and strawberry sample analysis, whole fruits were blended and five grams of the homogenate were accurately weighted in a $15 \mathrm{~mL}$ centrifuge tube and extracted twice by $1 \mathrm{~min}$ 150 vortex mixing of the homogenate using $5.0 \mathrm{~mL}$ methanol. The extracts were centrifuged at 3500 rpm for $5 \mathrm{~min}$, the pooled volume of supernatant was measured, and an aliquot was diluted 1:250 with deionized water. Grape must was directly diluted 1:50 with deionized water without solvent extraction. Immunoassays were performed under the following ic-ELISA conditions. Plates were coated with $0.1 \mathrm{mg} / \mathrm{L} \mathrm{OVA}-\mathrm{FHo} 4(\mathrm{MR}=5)$ and $50 \mu \mathrm{L}$ of sample dilution or diluted sample extract 155 was mixed with $50 \mu \mathrm{L}$ of FHo4\#27 antibody solution $(25 \mu \mathrm{g} / \mathrm{L})$ in $200 \mathrm{mM}$ sodium phosphate 
buffer, pH 7.4 with $0.05 \%$ Tween 20 . Thus, an additional one-half dilution of the sample extracts occurred upon assaying. Samples were run in triplicate wells. All other conditions were as previously described.

\subsection{HPLC reference procedure}

Twenty grams of homogenized sample (or $20 \mathrm{~mL}$ of grape must), $4 \mathrm{~g}$ of sodium chloride, $0.4 \mathrm{~mL}$ of $5 \mathrm{~N}$ hydrochloric acid solution, and $40 \mu \mathrm{L}$ internal standard (100 mg/L PPU in methanol) were mixed in a $50 \mathrm{~mL}$ centrifuge tube. Samples were extracted three times with $15 \mathrm{~mL}$ acetonitrile by $1 \mathrm{~min}$ vortex mixing and centrifuged at $3500 \mathrm{rpm}$ for $5 \mathrm{~min}$. The three acetonitrile extracts were pooled in a round-bottom flask, dried with anhydrous magnesium sulphate, evaporated until dryness in a rotary evaporator, and finally reconstituted in $0.4 \mathrm{~mL}$ methanol and filtered into a $2 \mathrm{~mL}$ amber glass vial through a $0.22 \mu \mathrm{m}$ glass-nylon syringe filter, so that a 50 -fold final concentration factor was achieved. Chromatographic separation was accomplished with a methanol:water mobile phase gradient from $50 \%$ to $90 \%$ methanol in 10 minutes and then $90 \%$ methanol during 5 min, at a flow rate of $1 \mathrm{~mL} / \mathrm{min}$. An injection loop of $20 \mu \mathrm{L}$ was employed and measurement wavelengths were 210 and $255 \mathrm{~nm}$ for $\mathrm{FH}$ and the internal standard, respectively.

\section{Results and discussion}

\subsection{Monoclonal antibody selection}

Animal immunization, cell fusion, hybridoma selection and cloning, and protein purification procedures to generate mAbs against $\mathrm{FH}$ were published in a previous paper (Mercader et al., 2009). For the present study, seven mAbs (FHo4\#21, FHo4\#22, FHo4\#23, FHo4\#24, FHo4\#26, FHo4\#27, and FHo4\#42) were affinity purified and bidimensional competitive assays were performed with 0.1 and $1.0 \mathrm{mg} / \mathrm{L}$ of OVA conjugate $(\mathrm{MR}=5)$ solution for plate coating. The competitive step was run with each antibody using serial dilutions of FH and 10, 30, 100, or 300 
$\mu \mathrm{g} / \mathrm{L}$ of $\mathrm{mAb}$. Therefore, one inhibition curve was obtained for every combination of reagents, so a global view of the analyte binding properties of all antibodies could be observed. Table 2 lists the curve parameters of the assay at two mAb concentrations, one of them affording the $A_{\max }$ value immediately above 1.0 and the other one giving the first-found $A_{\max }$ value below 1.0. The lower asymptotes of the curves were always equivalent to the background. For all of the mAbs, $\mathrm{IC}_{50}$ values below $1.0 \mu \mathrm{g} / \mathrm{mL}$ were attained, with values as low as $0.12 \mu \mathrm{g} / \mathrm{L}$ for mAb FHo4\#27. Lower $\mathrm{IC}_{50}$ values for $\mathrm{FH}$ were accomplished when the OVA-FHo4 coating conjugate was used at 0.1 $\mathrm{mg} / \mathrm{L}$. The only exception was mAb FHo4\#42 because it afforded comparable $\mathrm{IC}_{50}$ values at the two assayed coating-conjugate concentrations. Also, regarding the slopes of the inhibition curves, it was seen that they were all close to 1.00 and no generic dependence could be assigned, either to the coating-conjugate concentration or to the antibody concentration. Interestingly, the required concentrations of antibodies FHo4\#21, FHo4\#22, and FHo4\#27 were almost equivalent at the two assayed coating-conjugate concentrations. From this study, it could be concluded that the best assay

195 (lowest $\mathrm{IC}_{50}$ value and slope nearest to 1.0) was achieved with mAb FHo4\#27 and OVA-FHo4 conjugate at a coating concentration of $0.1 \mathrm{mg} / \mathrm{L}$. These conditions were used for further assay characterization.

\subsection{Antibody characterization}

\subsubsection{Selectivity}

A cross-reactivity study was performed in order to find other pesticides that could be recognized by antibody FHo4\#27. Since there are no commercial fungicides with a molecular structure similar to that of $\mathrm{FH}$, the studied compounds were fungicides which may be encountered together with FH in fruit samples, such as kresoxim-methyl, trifloxystrobin, pyraclostrobin, procymidone, azoxystrobin, picoxystrobin, boscalid, dimoxystrobin, and fluoxastrobin. Calibration curves were prepared with every compound in PBS but no inhibition was observed up to $1 \mu \mathrm{M}$ with 
any of them. Consequently, interferences from other fungicides are not expected in the application of the studied immunoassay to the determination of FH in food samples.

\subsubsection{Tolerance to solvents}

Organic solvents are required to extract pesticide residues from solid foodstuffs. However, the presence of small amounts of solvents in the final extract may have a considerable effect over the results attained by competitive immunoassays. Thus, the influence of most relevant organic solvents over the parameters of the selected immunoassay was studied. Methanol, ethanol,

215 acetonitrile, and DMF were evaluated at concentrations ranging from 0.5 to $10.0 \%$. FH standard curves were prepared in PBS containing different concentrations of solvent and they were mixed in the plate wells with a solution of mAb FHo4\#27 at $60 \mu \mathrm{g} / \mathrm{L}$ in PBST. This study showed that the $A_{\max }$ value was not affected by the presence of any of the assayed solvents at the assayed concentrations ( $\mathrm{A}_{\max }$ values around 1.4 were obtained in all cases; data not shown). On the contrary,

220 the $\mathrm{IC}_{50}$ value rose with increasing solvent concentrations. As depicted in Fig. 2, methanol, acetonitrile, and DMF could be used up to $2 \%$ with a little decrease in sensitivity, but in the case of ethanol the assay tolerance was very low and the $\mathrm{IC}_{50}$ value increased quickly. Because concentrated stock solutions of the pesticides in DMF were employed to prepare the analyte standard solutions in buffer, a certain concentration $(\leq 0.1 \%)$ of this solvent was always present in

225 all assays. The obtained results demonstrated that such a small amount of DMF did not affect the sensitivity of our ic-ELISA and methanol and acetonitrile were shown to be convenient extraction solvents for ELISA analysis.

\subsubsection{Effect of $p H$ and ionic strength}

The influence of physicochemical parameters such as $\mathrm{pH}$ and ionic strength was evaluated following a monoparametric strategy. FH standard curves were prepared in water and solutions of FHo4\#27 antibody were prepared at $60 \mu \mathrm{g} / \mathrm{L}$ in buffers of different ionic strengths or $\mathrm{pH}$. In order 
to prepare different ionic strength buffered solutions, a $40 \mathrm{mM}$ sodium phosphate buffer, $\mathrm{pH} 7.4$ containing $2 \mathrm{M} \mathrm{NaCl}$ was serially diluted with the corresponding volume of the same buffer but

235 without $\mathrm{NaCl}$. The influence of $\mathrm{pH}$ was also checked using several buffers with constant ionic strength but different $\mathrm{pH}$ values. For this purpose, a solution of $40 \mathrm{mM}$ citrate, $40 \mathrm{mM}$ disodium hydrogen phosphate, and $40 \mathrm{mM}$ Tris, $\mathrm{pH} 9.9$, was prepared. This buffered solution (pH 9.9) was used to prepared buffers at different $\mathrm{pH}$ values using $\mathrm{HCl}$, and different volumes of $2 \mathrm{M} \mathrm{NaCl}$ were added to keep the ionic strength constant at $175 \mathrm{mM}$. All these buffers also contained $0.05 \%$ Tween

240 20. Fig. 3 shows the observed changes in the $\mathrm{A}_{\max }$ and the $\mathrm{IC}_{50}$ values when the different studied buffers were used. As it can be seen, ionic strength values lower than that of PBS significantly increased the $\mathrm{IC}_{50}$ value, whereas the $\mathrm{A}_{\max }$ value rose smoothly. On the contrary, buffers with ionic strength values higher than that of PBS did not modify the $\mathrm{IC}_{50}$ value, whereas the $\mathrm{A}_{\max }$ was only slightly reduced, meaning that the sensitivity of the assay was maintained even at ionic strength 245 values higher than $500 \mathrm{mM}$. Also, $\mathrm{pH}$ values between 6.5 and 8.5 were quite well tolerated by the developed ic-ELISA. However, a considerable decrease of the absorbance signal was found at $\mathrm{pH}$ values lower than 6.5. Accordingly, the use of a strong buffer system enabling neutralization of acidic fruit samples by dilution would be advisable. Thus, for food sample analysis, the assay buffer (PBS) was substituted by sodium phosphate buffer, $\mathrm{pH} 7.4$ at an assay concentration of $100 \mathrm{mM}$, 250 thus keeping a similar ionic strength.

\subsection{ELISA analytical features}

For further ic-ELISA development, two OVA-FHo4 conjugates were evaluated with different hapten-to-protein ratios $(M R=5$ or 1$)$. As shown above (Table 2), the best performance of 255 the conjugate with a MR of 5 was achieved at $0.1 \mathrm{mg} / \mathrm{L}$ coating concentration, whereas for the low MR conjugate, the coating concentration had to be raised to $1.0 \mathrm{mg} / \mathrm{L}$ in order to get the equivalent $\mathrm{A}_{\max }$ value. The optimum concentration of mAb FHo4\#27 was also determined in each case (22 and $25 \mu \mathrm{g} / \mathrm{L}$ of $\mathrm{mAb}$ if the conjugate with MR of 1 and 5 was used, respectively) to reach an $\mathrm{A}_{\max }$ value 
between 1.0 and 1.5 in the absence of fungicide. Analyte solutions were prepared in water using

260 analytical standards, whereas antibody solutions were prepared in $200 \mathrm{mM}$ sodium phosphate buffer, pH 7.4 containing $0.05 \%$ Tween 20 . Fig. 4 shows the inhibition curves obtained with each conjugate. No significant differences were observed between the assays performed using an OVA conjugate prepared at a low MR or using an OVA conjugate prepared at a higher MR. The assay using a conjugate with a lower MR afforded an inhibition curve with a slope of 1.03 and an $\mathrm{IC}_{50}$

265 value of $0.31 \mu \mathrm{g} / \mathrm{L}$, whereas if the coating conjugate with a higher MR was used, the curve parameters were 1.09 and $0.27 \mu \mathrm{g} / \mathrm{L}$ for the slope and the $\mathrm{IC}_{50}$, respectively. The lower asymptote of the inhibition curves were 4.8 and $6.8 \%$ of the $A_{\max }$ for the assays using coating conjugates with low and high MRs, respectively. Finally, the limit of detection (LOD) was estimated as the concentration of $\mathrm{FH}$ that provided a $10 \%$ reduction of the $\mathrm{A}_{\max }$. The calculated LOD for the 270 developed ic-ELISA, using mAb FHo4\#27, was $0.04 \mu \mathrm{g} / \mathrm{L}$ for $\mathrm{FH}$ determinations in buffer, independently of the MR of the OVA-FHo4 conjugate that was employed.

\subsection{Evaluation of matrix effects}

Pesticide determinations in fruit and vegetable samples by immunoassay often require a 275 previous dilution step to avoid matrix interferences. Fruit samples were first measured by the described HPLC procedure in order to check for the absence of FH residues. Whole kiwifruit and strawberry samples were chopped and homogenized, centrifuged at $3500 \mathrm{rpm}$ for $5 \mathrm{~min}$, and the juices were collected for their analysis. Grape must and the obtained kiwifruit and strawberry juices were diluted $(1: 5,1: 25,1: 50,1: 250$, and 1:500) with deionized water and a FH standard curve was prepared with each sample dilution. From this study, it was observed that complete inhibition curves without interferences were reached when a 1:50 or higher dilution of grape must was carried out, whereas for kiwifruit and strawberry juices at least a 1:250 dilution in water was required (results not shown). Given the high affinity of the produced mAb, the applicability of the ic-ELISA was not compromised by the dilution factors that were required to eliminate these matrix effects. 


\subsection{Recovery studies}

Chromatographic analysis of pesticides in food often needs a previous extraction of the residues using an organic solvent for quantitative recovery of the analyte, particularly from solid fruit samples when no juice can easily be pressed out. For this reason, a study was undertaken using 290 different buffers and organic solvents to extract the homogenized samples. Two FH-containing kiwifruit samples (0.3 and $0.7 \mathrm{mg} / \mathrm{kg}$, previously measured by HPLC) and two FH-spiked strawberry samples $(0.5$ and $1.0 \mathrm{mg} / \mathrm{kg})$ were employed for this purpose. Homogenated samples were accurately weighted and extracted in triplicate experiments using $5.0 \mathrm{~mL}$ of deionized water, $200 \mathrm{mM}$ sodium phosphate buffer ( $\mathrm{pH} 7.4), 50 \mathrm{mM}$ carbonate buffer ( $\mathrm{pH} \mathrm{9.6),} \mathrm{acetonitrile,} \mathrm{or}$ methanol. Samples were centrifuged and a fraction of the supernatant was diluted 1:500 with deionized water to completely avoid the observed matrix interferences. Fig. 5 shows the FH recoveries obtained for the studied buffers and solvents. As it was expected, organic solvents provided higher extraction yields than aqueous buffers. Among the assayed solvents, acetonitrile and methanol afforded the best extraction yields. When just one extraction with methanol was done, the recoveries ranged from 53 to $81 \%$. However, a second extraction with methanol afforded quantitative recoveries (84-104\%; Fig. 5). Hence, methanol was selected for further studies because of its lower influence on the FH inhibition curve. To verify matrix effects of fruit extracts obtained by the optimized extraction procedure, FH-free fruit samples were extracted twice with methanol, diluted with deionized water $(1: 5,1: 50$, and 1:250), and FH standard curves were run with the diluted fruit extracts. Fig. 6 shows that no matrix effects were observed if a 1:250 dilution of the extracts in water was done, as it was also found in the preliminary study of the matrix effects using directly diluted fruit juices.

To determine the limit of quantification (LOQ), the direct dilution procedure was applied to the analysis of grape must samples, whereas kiwifruits and strawberries were processed by double extraction with methanol. Grape must and homogenized kiwifruit and strawberry samples were 
spiked with $\mathrm{FH}$ at $5,10,25,100,500$, and $2000 \mu \mathrm{g} / \mathrm{kg}$ and measured by the developed ic-ELISA. Unspiked samples were also included in every experiment as negative controls. The calculated recoveries of these assays are listed in Table 3. As it can be seen, quantitative results were achieved, with recovery values ranging from 100 to $110 \%$ for grape must, from 103 to $115 \%$ for kiwifruit, and from 108 to $111 \%$ for strawberry samples. From these results, the LOQ - considered as the lowest assayed FH concentrations that afforded recovery values between 80 and $120 \%$ - for grape must, kiwifruits, and strawberries was set at 5,10 , and $25 \mu \mathrm{g} / \mathrm{kg}$, respectively, around 1000 times lower than the European MRLs.

\subsection{HPLC analytical features}

A calibration curve was established from the peak area values of external standards with concentrations ranging from 0.5 to $100.0 \mathrm{mg} / \mathrm{L}$ in methanol. The detector response was linear over the considered concentration range (the correlation coefficient was 0.999), and the LOQ, set at the concentration of $\mathrm{FH}$ that provided a signal-to-noise ratio of 10 , was $20 \mu \mathrm{g} / \mathrm{kg}$ for grape must and kiwifruits, and $50 \mu \mathrm{g} / \mathrm{kg}$ for strawberry samples. Recovery studies of the HPLC procedure were performed with grape must, kiwifruit, and strawberry fungicide-free samples spiked with FH at 50, 100 , and $1000 \mu \mathrm{g} / \mathrm{kg}$. In this case, the recoveries ranged from 90 to $106 \%$ (results not shown).

\subsection{Validation of the developed ic-ELISA}

FH residues in fruit samples acquired in a public market were measured by our ic-ELISA and the reference HPLC procedure. For comparison, the sample set consisted of 10 kiwifruit and 7 strawberry samples in which residues of FH had been previously detected. Whole fruit homogenates were extracted twice with methanol and diluted 1:250 with deionized water for ic-ELISA determinations, whereas for HPLC measurements samples were extracted as described in the Materials and Methods section. Table 4 lists the contents of FH found with each method, ranging from 0.1 to $5.0 \mathrm{mg} / \mathrm{kg}$. Although some of the observed concentrations were actually high, no 
samples exceeding the MRLs established by the European Commission were found (EC Regulation, 2008). The contents of FH measured by ic-ELISA highly corresponded to those found by HPLC. In fact, the linear regression analysis between ELISA and HPLC data, shown in Fig. 7, followed the equation: $\mathrm{C}_{\mathrm{ELISA}}=(0.00 \pm 0.11)+(0.99 \pm 0.05) * \mathrm{C}_{\mathrm{HPLC}}\left(\mathrm{r}^{2}=0.990, \mathrm{n}=17\right)$, where $\mathrm{C}_{\mathrm{ELISA}}$ is the $\mathrm{FH}$ concentration (in $\mathrm{mg} / \mathrm{kg}$ ) attained by our ic-ELISA and $\mathrm{C}_{\mathrm{HPLC}}$ is the corresponding concentration obtained by HPLC. Concerning each of the two fruit commodities, excellent correlation between both methods was also found: i) $\mathrm{C}_{\mathrm{ELISA}}=(0.05 \pm 0.16)+(0.98 \pm 0.06) * \mathrm{C}_{\mathrm{HPLC}},\left(\mathrm{r}^{2}=0.991, \mathrm{n}=10\right)$

for kiwifruits and ii) $\mathrm{C}_{\mathrm{ELISA}}=(-0.08 \pm 0.17)+(1.01 \pm 0.09) * \mathrm{C}_{\mathrm{HPLC}},\left(\mathrm{r}^{2}=0.990, \mathrm{n}=7\right)$ for

345 strawberries. The equivalence of the two applied methodologies demonstrated the suitability of the developed immunoassay for the analysis of FH residues in fruits.

To further prove the sensitivity and applicability of the immunochemical method, the degree of penetration of $\mathrm{FH}$ into the edible portion of kiwifruits was studied. To this purpose, four individual pieces of fruit with incurred residues were sliced into two halves and separately extracted and analyzed by ELISA, one of them including the skin, as officially indicated, and the other half after being peeled. Determinations by immunoassay showed that the FH concentration in the edible part of kiwifruit represents $4.7 \pm 1.7 \%$ of the amount found in the whole fruit.

\section{Conclusions}

In a previous article, a simple strategy to synthesize a FH derivative was described. This hapten was successfully used to generate a collection of high-affinity mAbs (Mercader et al., 2009). In the present study, one of these antibodies (FHo4\#27) was used to develop an ELISA in the conjugate-coated indirect competitive format, which was applied to the analysis of FH residues in 360 liquid and solid fruit samples. This assay was highly selective and it was shown to tolerate neutral and moderately alkaline $\mathrm{pH}$ values, as well as elevated salt concentrations. Matrix effects caused by these two physicochemical parameters could easily be avoided by sample dilution in the appropriate 
assay buffer. Although the sensitivity of the assay notably decreased by the presence of ethanol, other solvents such as methanol, acetonitrile, and DMF were well tolerated up to $2 \%$. For liquid samples like grape must, the LOQ of the assay for FH after a simple dilution in water was $5 \mu \mathrm{g} / \mathrm{kg}$. For solid samples such as kiwifruits and strawberries, the LOQ for FH was 10 and $25 \mu \mathrm{g} / \mathrm{kg}$, respectively, when a double extraction procedure with methanol was done. Also, the accuracy of the optimized ic-ELISA was demonstrated by comparison with a reference procedure based on HPLC using incurred fruit samples. A summary of the advantages and drawbacks of both methodologies is listed in Table 5, highlighting the developed ic-ELISA as a simple, cheap, reliable, and rapid method for the analysis of FH in food samples.

\section{Acknowledgements}

This work was financed by Generalitat Valenciana (GVPRE/2008/236) and Ministerio de Educación y Ciencia (AGL2006-12750-C02-01/ALI) and cofinanced by FEDER funds. J.V. Mercader and F. A. Esteve-Turrillas were hired by the CSIC; the former under a contract of the I3P Program and the latter under the Juan de la Cierva Program of the Spanish Ministry of Innovation and Science and cofinanced by the European Social Fund. Limited amounts of the described immunoreagents are available upon request. 


\section{Bibliography}

Anastassiades, M., Lehotay, S. J., Štajnbaher, D., \& Schenck, F. J. (2003). Fast and easy multiresidue method employing acetonitrile extraction/partitioning and "Dispersive SolidPhase Extraction" for the determination of pesticide residues in produce. Journal of AOAC International, 86(2), 412-431.

Arysta LifeScience. http://www.arystalifescience.com

Bayer CropScience. http://www.bayercropscience.com

Cabras, P., Angioni, A., Garau, V. L., Pirisi, F. M., Cabitza, F., Pala, M., \& Farris, G. A. (2001). Fenhexamid residues in grapes and wine. Food Additives and Contaminants, 18(7), 625-629.

Christensen, H. B., Granby, K., \& Rabolle, M. (2003). Processing factors and variability of pyrimethanil, fenhexamid and tolylfluanid in strawberries. Food Additives and Contaminants, 20(8), 728-741.

Čuš, F., Česnik, H. B., Bolta, S. V., \& Gergorčič, A. (2010). Pesticide residues and microbiological quality of bottled wines. Food Control, 21, 150-154.

European Commission Regulation (2008). (EC) Nr. 839/2008 of 31 July 2008 amending Regulation (EC) Nr. 396/2005 of the European Parliament and of the Council as regards Annexes II, III and IV on maximum residue levels of pesticides in or on certain products. Official Journal of the European Union, 51, L 234.

EFSA Scientific Report (2009) 305, 1-116.

FAO/WHO (2005). Report of the Joint Meeting of the FAO Panel of Experts on Pesticide Residues in Food and the Environment and the WHO Core Assessment Group on Pesticide Residues. Geneva, Switzerland.

Hengel, M., Hung, B., Engebretson, J., \& Shibamoto, T. (2003). Analysis of Fenhexamid in Caneberry, Blueberry, and Pomegranate by Liquid Chromatography-Tandem Mass Spectrometry. Journal of Agricultural and Food Chemistry, 51(23), 6635-6639. 
Kmellár, B., Fodor, P., Pareja, L., Ferrer, C., Martínez-Uroz, M. A., Valverde, A., \& FernandezAlba, A. R. (2008). Validation and uncertainty study of a comprehensive list of 160 pesticide residues in multi-class vegetables by liquid chromatography-tandem mass spectrometry. Journal of Chromatography A, 1215, 37-50.

Lesueur, C., Knittl, P., Gartner, M., Mentler, A., \& Fuerhacker, M. (2008). Analysis of 140 pesticides from conventional farming foodstuff samples after extraction with the modified QuECheRS method. Food Control, 19, 906-914.

Likas, D. T., Tsiropoulos, N. G., \& Miliadis, G. E. (2007). Rapid gas chromatographic method for the determination of famoxadone, trifloxystrobin and fenhexamid residues in tomato, grape and wine samples. Journal of Chromatography A, 1150, 208-214.

Mercader, J. V., \& Abad-Fuentes, A. (2009). Monoclonal Antibody Generation and Direct Competitive Enzyme-Linked Immunosorbent Assay Evaluation for the Analysis of the Fungicide Fenhexamid in Must and Wine. Journal of Agricultural and Food Chemistry, $57(12), 5129-5135$.

Mercader, J. V., Suárez-Pantaleón, C., Agulló, C., Abad-Somovilla, A., \& Abad-Fuentes, A. (2008). Production and Characterization of Monoclonal Antibodies Specific to the Strobilurin Pesticide Pyraclostrobin. Journal of Agricultural and Food Chemistry, 56(17), $7682-7690$.

425 Nüßlein, F. (1999). Method for liquid-chromatographic determination of the fungicidal active ingredient fenhexamid (KBR 2738) in plant materials. Pflanzenschutz-Nachrichten Bayer, $52(2), 187-226$.

Park, Y. S., Abd El-Aty, A. M., Choi, J. H., Cho, S. K., Shin, D. H., \& Shim, J. H. (2007). Pesticide multiresidue analysis in Panax ginseng (C. A. Meyer) by solid-phase extraction and gas chromatography with electron capture and nitrogen-phosphorus detection. Biomedical Chromatography, 21, 29-39. 
Rabolle, M., Spliid, N. H., Kristensen, K., \& Kudsk, P. (2006). Determination of Fungicide Residues in Field-Grown Strawberries following Different Fungicide Strategies against Gray Mold (Botrytis cinerea). Journal of Agricultural and Food Chemistry, 54(3), 900-908.

435 Rial Otero, R., Cancho Grande, B., \& Simal Gandara, J. (2003). Multiresidue method for fourteen fungicides in white grapes by liquid-liquid and solid-phase extraction followed by liquid chromatography-diode array detection. Journal of Chromatography A, 992, 121-131.

Roßlenbroich, H. J. (1999). Efficacy of fenhexamid (KBR 2738) against Botrytis cinerea and related fungal pathogens. Pflanzenschutz-Nachrichten Bayer, 52(2), 127-144.

440 Suty, A., Pontzen, R., \& Stenzel, K. (1999). Fenhexamid - Sensitiviy of Botrytis cinerea: Determination of baselin sensitiviy and assessment of the risk of resistance. PflanzenschutzNachrichten Bayer, 52(2), 145-157.

Sannino, A., Bolzoni, L., \& Bandini, M. (2004). Application of liquid chromatography with electrospray tandem mass spectrometry to the determination of a new generation of pesticides in processed fruits and vegetables. Journal of Chromatography A, 1036, 161-169. 


\section{Figure captions}

450 Fig. 1. Molecular structures of FH (upper) and hapten FHo4 (lower).

Fig. 2. Influence of organic solvents over the ic-ELISA inhibition curve.

Fig. 3. Effect of the buffer ionic strength and $\mathrm{pH}$ on the ic-ELISA inhibition curve.

455

Fig. 4. ic-ELISA inhibition curves for FH using OVA-conjugates with different hapten-to-protein MR.

Fig. 5. Recovery values of FH in kiwifruit and strawberry samples extracted with several buffers or 460 organic solvents and measured by ic-ELISA.

Fig. 6. Interferences produced by kiwifruit and strawberry methanolic extracts diluted in water over the developed ic-ELISA.

465 Fig. 7. Comparative study between ic-ELISA and HPLC results obtained for FH determination in kiwifruit $(\bullet)$ and strawberry $(\boldsymbol{\Delta})$ samples. 


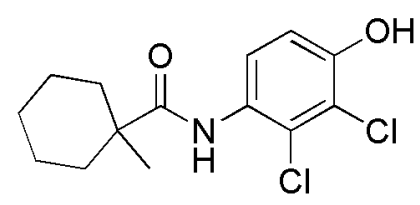<smiles>CC1(C(=O)Nc2ccc(OCCCC(=O)O)c(Cl)c2Cl)CCCCC1</smiles>

Figure 1.

Esteve-Turrillas, Abad-Fuentes \& Mercader 


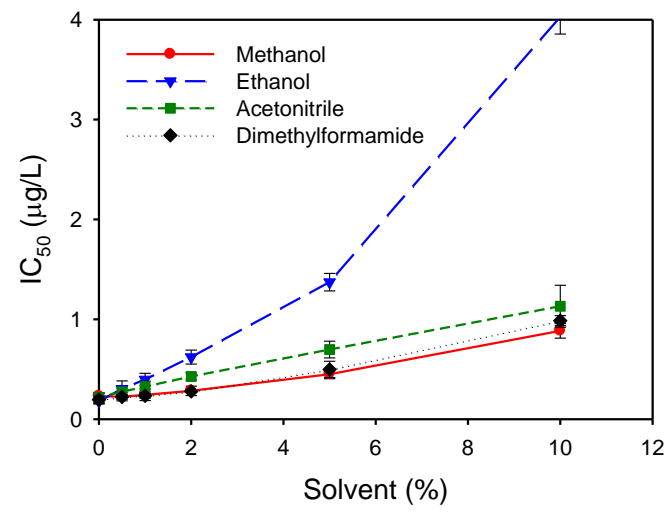

Figure 2.

Esteve-Turrillas, Abad-Fuentes \& Mercader 

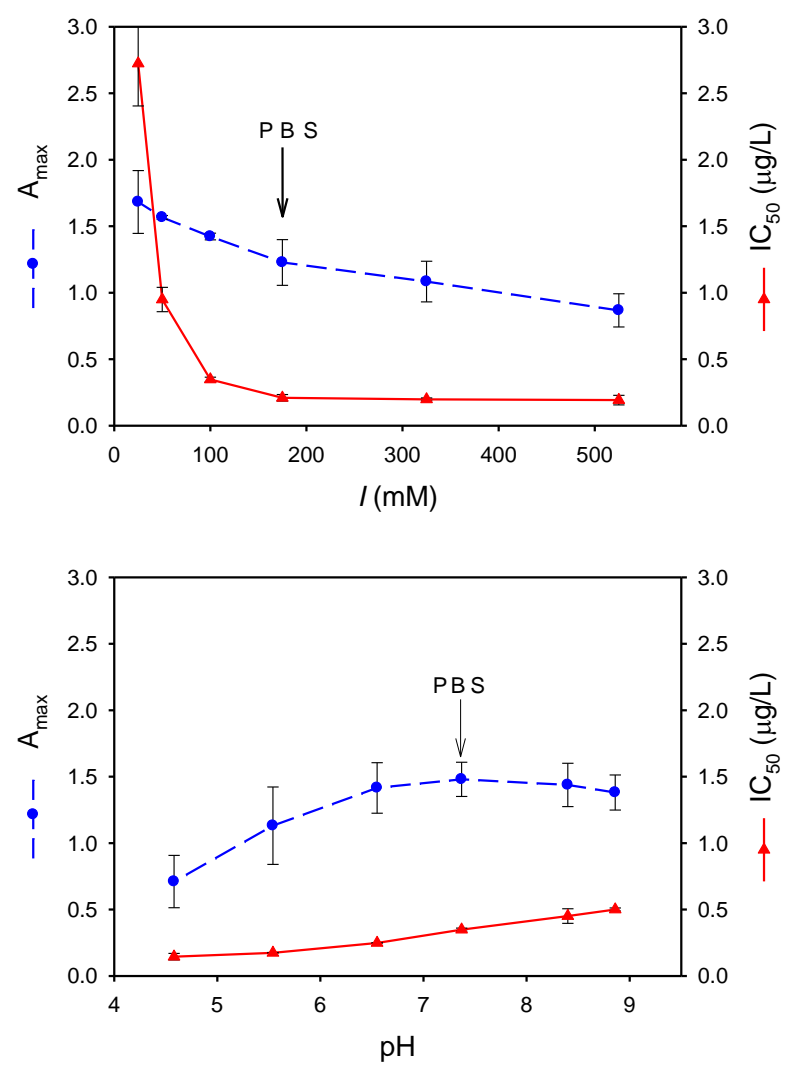

Figure 3.

Esteve-Turrillas, Abad-Fuentes \& Mercader 


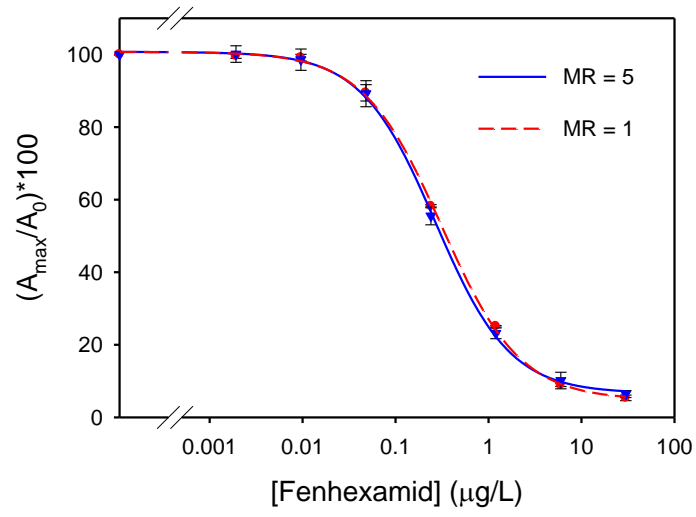

Figure 4

Esteve-Turrillas, Abad-Fuentes \& Mercader 


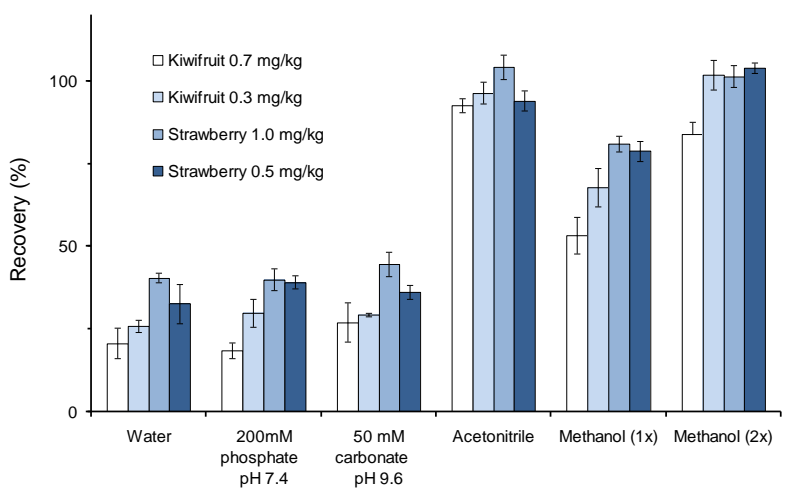

Figure 5.

Esteve-Turrillas, Abad-Fuentes \& Mercader 

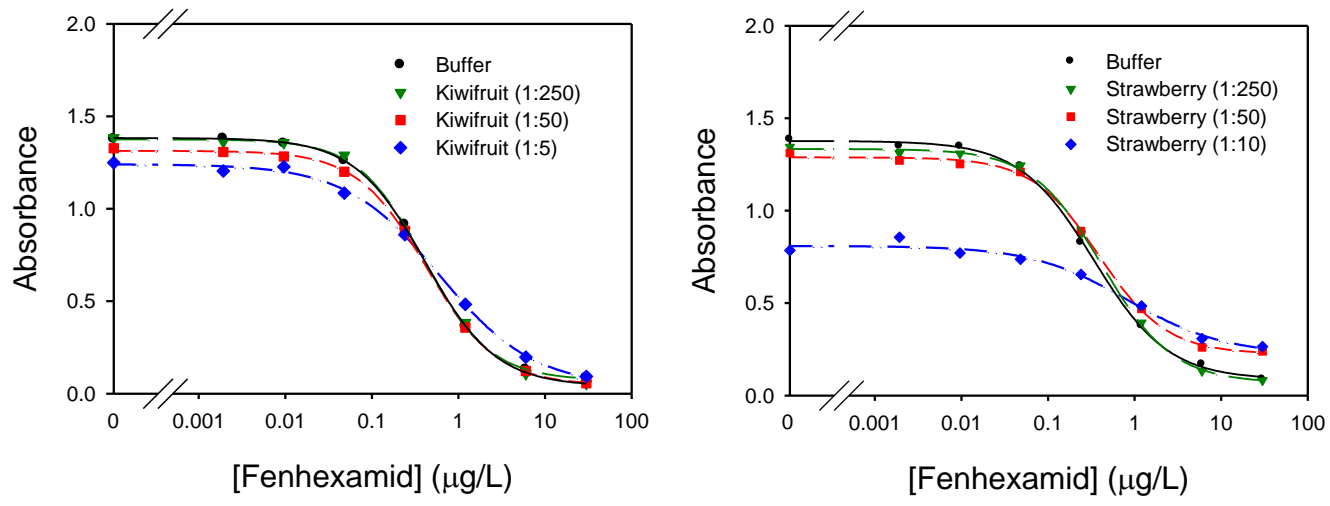

Figure 6.

Esteve-Turrillas, Abad-Fuentes \& Mercader 


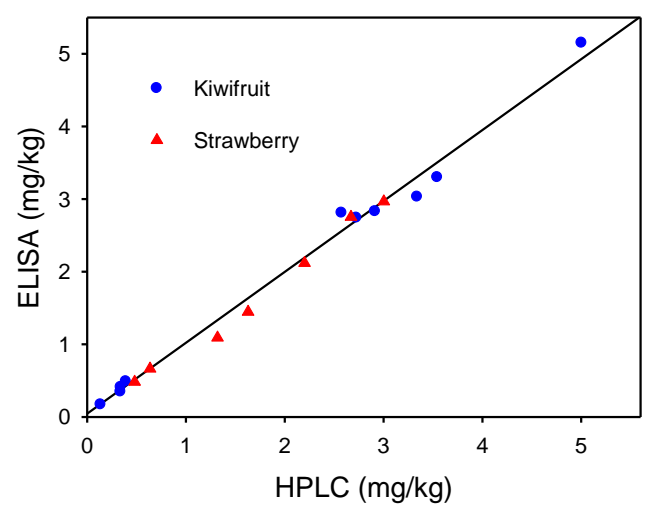

Figure 7.

Esteve-Turrillas, Abad-Fuentes \& Mercader 


\section{Table 1}

Published procedures for the analysis of $\mathrm{FH}$ in fruits and vegetables.

\begin{tabular}{|c|c|c|c|c|c|}
\hline Sample & Sample treatment & Determination & $\begin{array}{c}\text { Recovery } \\
(\%)\end{array}$ & $\begin{array}{c}\mathrm{LOQ} \\
(\mu \mathrm{g} / \mathrm{kg})\end{array}$ & Ref. \\
\hline Vegetables & SPE & HPLC-UV & $69-110$ & 20 & Nüßlein, 1999 \\
\hline Grapes, must, wine & LLE & GC-NPD & $82-111$ & 100 & Cabras et al., 2001 \\
\hline Strawberry & USE & HPLC-MS-MS & $94-99$ & 10 & Christensen et al., 2003 \\
\hline Grapes & LLE + SPE & HPLC-DAD & 41 & 50 & Rial Otero et al., 2003 \\
\hline Caneberry, blueberry, pomegranate & $\mathrm{UTH}+\mathrm{SPE}+\mathrm{LLE}$ & HPLC-MS-MS & $72-105$ & 20 & Hengel et al., 2003 \\
\hline Apple, lemon, tomato & UTH + LLE & HPLC-MS-MS & $82-92$ & 10 & Sannino et al., 2004 \\
\hline Strawberry & UTH & HPLC-MS & $86-95$ & 1 & Rabolle et al., 2006 \\
\hline Tomato, grapes, wine & LLE & GC-ECD & $81-102$ & 20 & Likas et al., 2007 \\
\hline Panax ginseng & UTH + SPE & GC-ECD & $99-112$ & 3 & Park et al., 2007 \\
\hline Grapes, lemon, onion, tomato & QUEChERS & GC-MS & $83-119$ & 1 & Lesueur et al., 2008 \\
\hline Tomato, pear, orange & QuEChERS & HPLC-MS-MS & $80-110$ & 5 & Kmellár et al., 2008 \\
\hline Grape juice, wine & Dilution & ELISA & $95-118$ & 30 & Mercader et al., 2009 \\
\hline
\end{tabular}


Table 2

Assay parameters obtained from the bidimensional competitive analysis.

\begin{tabular}{|c|c|c|c|c|c|c|c|c|}
\hline \multirow[b]{2}{*}{$\mathrm{mAb}$} & \multicolumn{4}{|c|}{ OVA-FHo4 at $0.1 \mathrm{mg} / \mathrm{L}$} & \multicolumn{4}{|c|}{ OVA-FHo4 at $1.0 \mathrm{mg} / \mathrm{L}$} \\
\hline & $\begin{array}{c}\text { mAb conc. } \\
(\mu \mathrm{g} / \mathrm{L})\end{array}$ & $A_{\max }$ & Slope & $\begin{array}{c}\mathrm{IC}_{50} \\
(\mu \mathrm{g} / \mathrm{L})\end{array}$ & $\begin{array}{c}\text { mAb conc. } \\
(\mu \mathrm{g} / \mathrm{L})\end{array}$ & $A_{\max }$ & Slope & $\begin{array}{c}\mathrm{IC}_{50} \\
(\mu \mathrm{g} / \mathrm{L})\end{array}$ \\
\hline \multirow[t]{2}{*}{ FHo4\#21 } & 10 & 0.57 & 1.08 & 0.50 & 10 & 0.76 & 1.28 & 3.04 \\
\hline & 30 & 1.18 & 1.09 & 0.60 & 30 & 1.68 & 1.12 & 3.67 \\
\hline \multirow[t]{2}{*}{$\mathrm{FHo4 \# 22}$} & 10 & 0.70 & 0.92 & 0.26 & 10 & 0.88 & 1.10 & 1.75 \\
\hline & 30 & 1.65 & 0.89 & 0.37 & 30 & 2.08 & 0.94 & 2.71 \\
\hline \multirow[t]{2}{*}{ FHo4\#23 } & 30 & 0.68 & 1.00 & 0.50 & 10 & 0.73 & 0.74 & 1.70 \\
\hline & 100 & 1.45 & 0.94 & 0.64 & 30 & 1.84 & 0.78 & 1.90 \\
\hline \multirow[t]{2}{*}{ FHo4\#24 } & 30 & 0.68 & 1.00 & 0.53 & 10 & 0.36 & 1.14 & 3.92 \\
\hline & 100 & 1.42 & 0.91 & 0.63 & 30 & 1.04 & 1.08 & 4.76 \\
\hline \multirow[t]{2}{*}{ FHo4\#26 } & 30 & 0.63 & 0.99 & 0.25 & 10 & 0.48 & 1.10 & 0.88 \\
\hline & 100 & 1.36 & 0.95 & 0.39 & 30 & 1.26 & 0.83 & 1.12 \\
\hline \multirow[t]{2}{*}{ FHo4\#27 } & 10 & 0.60 & 0.88 & 0.12 & 10 & 0.48 & 1.33 & 1.35 \\
\hline & 30 & 1.40 & 0.96 & 0.19 & 30 & 1.30 & 1.14 & 1.28 \\
\hline \multirow[t]{2}{*}{ FHo4\#42 } & 100 & 0.89 & 1.02 & 0.50 & 10 & 0.44 & 0.90 & 0.88 \\
\hline & 300 & 1.84 & 1.25 & 1.04 & 30 & 1.20 & 0.86 & 0.97 \\
\hline
\end{tabular}




\section{Table 3}

Recoveries by ic-ELISA using liquid and solid fruit samples spiked with FH at different levels.

\begin{tabular}{|c|c|c|c|}
\hline \multirow[b]{2}{*}{$\begin{array}{c}\text { Spiked } \\
(\mu \mathrm{g} / \mathrm{kg})\end{array}$} & \multicolumn{3}{|c|}{ Recovery $(\% \pm s, \mathrm{n}=4)$} \\
\hline & $\begin{array}{l}\text { Must } \\
(1: 50)\end{array}$ & $\begin{array}{c}\text { Kiwifruit } \\
(1: 250) \\
\end{array}$ & $\begin{array}{c}\text { Strawberry } \\
(1: 250)\end{array}$ \\
\hline 5 & $107 \pm 12$ & n.a. ${ }^{a}$ & n.a. \\
\hline 10 & $104 \pm 2$ & $113 \pm 14$ & $-b$ \\
\hline 25 & $100 \pm 5$ & $104 \pm 6$ & $108 \pm 13$ \\
\hline 100 & $104 \pm 8$ & $105 \pm 6$ & $109 \pm 11$ \\
\hline 500 & $110 \pm 20$ & $115 \pm 1$ & $116 \pm 3$ \\
\hline 2000 & n.a. & $103 \pm 3$ & $111 \pm 16$ \\
\hline
\end{tabular}

${ }^{a}$ Values not assayed. ${ }^{b}$ Below the quantitation range. 


\section{Table 4}

Fenhexamid contents found in kiwifruit and strawberry samples obtained from local markets.

\begin{tabular}{|c|c|c|c|}
\hline \multirow[b]{2}{*}{ Sample } & \multicolumn{2}{|c|}{$\begin{array}{l}\text { Fenhexamid concentration } \\
(\mathrm{mg} / \mathrm{kg} \pm s)\end{array}$} & \multirow[b]{2}{*}{ Bias (\%) } \\
\hline & $\operatorname{HPLC}(n=2)$ & ELISA $(n=3)$ & \\
\hline $\mathrm{K}^{\mathrm{a}} 1$ & $2.58 \pm 0.25$ & $2.81 \pm 0.18$ & 9.07 \\
\hline $\mathrm{K} 2$ & $2.73 \pm 0.14$ & $2.74 \pm 0.16$ & 0.54 \\
\hline K 3 & $3.54 \pm 0.35$ & $3.30 \pm 0.28$ & -6.94 \\
\hline K 4 & $0.39 \pm 0.03$ & $0.49 \pm 0.04$ & 23.96 \\
\hline K 5 & $3.34 \pm 0.06$ & $3.03 \pm 0.02$ & -9.31 \\
\hline K 6 & $0.14 \pm 0.00$ & $0.18 \pm 0.05$ & 23.74 \\
\hline K 7 & $2.91 \pm 0.18$ & $2.83 \pm 0.21$ & -2.91 \\
\hline K 8 & $5.00 \pm 0.16$ & $4.93 \pm 0.49$ & 2.91 \\
\hline K 9 & $0.34 \pm 0.02$ & $0.41 \pm 0.05$ & 19.79 \\
\hline K10 & $0.34 \pm 0.03$ & $0.35 \pm 0.03$ & 2.65 \\
\hline$S^{b_{1}}$ & $3.00 \pm 0.12$ & $2.97 \pm 0.09$ & -1.20 \\
\hline S 2 & $2.67 \pm 0.13$ & $2.75 \pm 0.03$ & 3.08 \\
\hline S 3 & $0.64 \pm 0.00$ & $0.66 \pm 0.05$ & 4.17 \\
\hline S 4 & $0.48 \pm 0.01$ & $0.48 \pm 0.03$ & 0.37 \\
\hline S 5 & $1.63 \pm 0.04$ & $1.45 \pm 0.12$ & -11.26 \\
\hline S 6 & $2.20 \pm 0.09$ & $2.12 \pm 0.16$ & -3.69 \\
\hline S 7 & $1.32 \pm 0.05$ & $1.09 \pm 0.09$ & -17.31 \\
\hline
\end{tabular}

${ }^{a}$ Kiwifruit. ${ }^{\mathrm{b}}$ Strawberry. 
Table 5

Comparison of the analytical features of the developed ic-ELISA and the reference HPLC procedure.

\begin{tabular}{|c|c|c|}
\hline Parameter & ic-ELISA & HPLC \\
\hline \multicolumn{3}{|l|}{ Time (h): } \\
\hline Pre-treatment & 0.25 & 0.50 \\
\hline Analysis & 2.25 & 0.25 \\
\hline $\begin{array}{l}\text { Sample throughput } \\
\text { (per hour) }\end{array}$ & $\begin{array}{c}38 \\
\text { per plate }\end{array}$ & 1.3 \\
\hline $\begin{array}{l}\text { Solvent consumption } \\
\text { (mL per sample) }\end{array}$ & $10^{\mathrm{a}}$ & 45 \\
\hline Dilution/concentration & $\begin{array}{l}1: 50^{\mathrm{b}} \\
1: 250\end{array}$ & $50: 1$ \\
\hline \multicolumn{3}{|l|}{ LOQ $(\mu \mathrm{g} / \mathrm{kg}):$} \\
\hline Must & 5 & 20 \\
\hline Kiwifruit & 10 & 20 \\
\hline Strawberry & 25 & 50 \\
\hline
\end{tabular}

